\title{
Fucoid Macroalgae Have Distinct Physiological Mechanisms to Face Emersion and Submersion Periods in Their Southern Limit of Distribution
}

\author{
Maria Martins ${ }^{1}$ * , Cristiano Soares ${ }^{2}$ (D) Inês Figueiredo ${ }^{2}$, Bruno Sousa ${ }^{1}$ (D) Ana Catarina Torres ${ }^{3}$, \\ Isabel Sousa-Pinto $^{3} \mathbb{D}$, Puri Veiga ${ }^{3}$, Marcos Rubal $^{3} \mathbb{D}$ and Fernanda Fidalgo ${ }^{1}$ (D)
}

1 GreenUPorto-Sustainable Agrifood Production Research Centre and INOV4AGRO, Biology Department, Faculty of Sciences University of Porto (FCUP), Rua do Campo Alegre, 4149-007 Porto, Portugal; bruno.filipe@fc.up.pt (B.S.); ffidalgo@fc.up.pt (F.F.)

2 Biology Department, Faculty of Sciences University of Porto (FCUP), Rua do Campo Alegre, 4149-007 Porto, Portugal; c.fsoares@fc.up.pt (C.S.); up201505847@fc.up.pt (I.F.)

3 Interdisciplinary Centre of Marine and Environmental Research (CIIMAR), University of Porto, Novo Edifício do Terminal de Cruzeiros do Porto de Leixões, Avenida General Norton de Matos, 4450-208 Matosinhos, Portugal; a_catarina_torres@hotmail.com (A.C.T.); ispinto@fc.up.pt (I.S.-P.); puri.sanchez@fc.up.pt (P.V.); marcos.garcia@fc.up.pt (M.R.)

* Correspondence: up201306375@fc.up.pt

Citation: Martins, M.; Soares, C.; Figueiredo, I.; Sousa, B.; Torres, A.C.; Sousa-Pinto, I.; Veiga, P.; Rubal, M.; Fidalgo, F. Fucoid Macroalgae Have Distinct Physiological Mechanisms to Face Emersion and Submersion Periods in Their Southern Limit of Distribution. Plants 2021, 10, 1892. https://doi.org/10.3390/ plants10091892

Academic Editors: Philippe Juneau and Marcelo Pedrosa Gomes

Received: 23 July 2021

Accepted: 9 September 2021

Published: 14 September 2021

Publisher's Note: MDPI stays neutral with regard to jurisdictional claims in published maps and institutional affiliations.

Copyright: (c) 2021 by the authors. Licensee MDPI, Basel, Switzerland. This article is an open access article distributed under the terms and conditions of the Creative Commons Attribution (CC BY) license (https:/ / creativecommons.org/licenses/by/ $4.0 /)$.

\begin{abstract}
During high tide, macroalgae are submersed, facing adequate environmental conditions, however, at low tide, these species can be exposed to high UV radiation and desiccation, leading to an overproduction of reactive oxygen species, causing oxidative stress. Since intertidal organisms present differential sensitivity to abiotic fluctuations, this study aimed to evaluate the physiological responses [photosynthetic pigments, hydrogen peroxide $\left(\mathrm{H}_{2} \mathrm{O}_{2}\right)$, lipid peroxidation (LP), and thiols and proline] of three macroalgae, from different intertidal levels, towards tidal regimes. Samples of Pelvetia canaliculata, Ascophyllum nodosum, and Fucus serratus were collected from beaches located on the southern limit of distribution in periods of potential stress (Summer and Spring), under low and high tide. The photosynthetic pigments of $P$. canaliculata and F. serratus were generally higher during low tide, and the oxidative damage evidenced by $\mathrm{H}_{2} \mathrm{O}_{2}$ and LP increased in the Summer, while $A$. nodosum showed greater oxidative damage in the Spring. While thiol content did not change, proline levels were species- and tidal-specific among sampling dates. P. canaliculata presented higher resilience to unfavorable conditions, while F. serratus was the most sensitive species. The physiological responses analyzed were species-specific, pointing to the high susceptibility of low intertidal organisms to expected extreme climatic events.
\end{abstract}

Keywords: Pelvetia canaliculata; Ascophyllum nodosum; Fucus serratus; intertidal macroalgae; oxidative stress

\section{Introduction}

Climate change can exert a significant role in coastal and marine ecosystems, affecting their structure and functioning. In coastal zones, macroalgae, as photosynthetic organisms, are one of the bases of marine food webs, essential for maintaining their regular functioning [1]. Most macroalgae species live in the intertidal zone of a rocky shore [2], a zone characterized by its high environmental instability, due to the accentuated fluctuations of environmental factors (e.g., temperature, salinity, desiccation, radiation) which will be exacerbated given the current climate change scenario. Thus, the capacity of these species to withstand the environmental challenges determines their distribution and abundance along the intertidal zone, allowing the organisms to survive and reproduce [2]. Moreover, understanding the physiological plasticity of intertidal seaweeds towards an ever-changing environment, where differences between tidal regimes are increasingly challenging, can 
provide important clues about how climate change will impact the distribution pattern of these organisms.

Intertidal macroalgae, as sessile organisms, are periodically subjected to UV radiation and high temperatures, due to desiccation during emersion, followed by submersion, where they face homeostasis-promoting conditions. As a consequence of extended desiccation, the efficiency of the photosystems I and II is disturbed, thus negatively affecting the photosynthetic rate [3]. These physiological disturbances disrupt the redox homeostasis by an overproduction of reactive oxygen species (ROS), that comprise different chemical species, including molecular [hydrogen peroxide $\left(\mathrm{H}_{2} \mathrm{O}_{2}\right)$ and singlet oxygen $\left({ }^{1} \mathrm{O}_{2}\right)$ ] and radical [superoxide anion $\left(\mathrm{O}_{2}{ }^{-}\right)$and hydroxyl radical $(\mathrm{OH} \cdot)$ ] forms [2,4]. Although ROS are constantly produced as a result of several metabolic processes, and at low concentrations, they are recognized as important signaling compounds, at high levels, they can be very harmful to the cells inducing the occurrence of oxidative stress. However, to prevent oxidative bursts, macroalgae developed a tightly regulated antioxidant (AOX) system, that includes a variety of enzymatic (e.g., superoxide dismutase-SOD, EC 1.15.1.1; catalaseCAT, EC 1.11.1.6; ascorbate peroxidase-APX, EC 1.11.1.11) and non-enzymatic (e.g., ascorbic acid-AsA; glutathione-GSH; proline) components [2,4]. Acting synergistically with each other, AOX enzymes and metabolites can reduce the harmful effects of ROS overproduction and accumulation, reestablishing redox homeostasis. Nonetheless, as a result of the severe and/or repeated stress events, there can be either an overproduction of ROS and/or an inhibition of the AOX defense, leading to ROS levels that exceed the AOX capacity of these organisms. As a consequence, lipid peroxidation (LP) can occur, causing damage to the membranes and the photosynthetic apparatus, in addition to promoting the degradation of nucleic acids and proteins [2,4].

Pelvetia canaliculata (L.) Decaisne and Thuret, Ascophyllum nodosum (L.) Le Jolis and Fucus serratus L. are three brown macroalgae species belonging to the Fucales family that inhabit the rocky intertidal shores and are widely distributed around the North Atlantic $[5,6]$. Pelvetia canaliculata, usually found at the upper limit of the intertidal [7], is known as one of the most stress-tolerant macroalgae species, as it can resist desiccation and rapidly acclimates to high radiation, mainly due to its carotenoid composition [7]. Ascophyllum nodosum and Fucus serratus, living in the mid-high and mid-low intertidal zone, respectively, play an important role in coastal ecosystems, as they provide food, habitat, and shelter for a variety of living beings, along with the supply of essential nutrients [5,6]. In addition, these two species, despite being ecologically and phylogenetically close, differ in their life-spans and growth rates, which may evidence different capacities for adaption and response to environmental constraints [5]. As the Iberian Peninsula is the southern distributional limit for these cold-water species and given that in recent decades this area has been largely affected by climate change [8], the abundance of these organisms in this area has been declining [9]. Thus, efforts need to be made to prevent future adaptations and/or shifts in the distribution of intertidal living beings. Up to date, the scientific community has been dedicated to unraveling the response of individual macroalgae species living in the intertidal and, in most studies, under controlled conditions [3,10-12]. However, research should be conducted under field conditions, i.e., a more realistic scenario, to better understand the physiological responses of macroalgae that live at distinct intertidal levels to the above-mentioned environmental fluctuations to unravel the adaptation mechanisms that these species employ to deal with the ever-changing conditions that they are subjected to.

Bearing in mind the influence of multiplicity of environmental constraints and the complexity of their interactions in the growth and development of P. canaliculata, A. nodosum, and F. serratus, the present study aimed to unravel the impact of the tidal regime on the physiological performance of these macroalgae species under field conditions. The main hypothesis that supports this work was that the three selected macroalgae species, depending on their position in the intertidal zone, possess distinct physiological mechanisms to overcome desiccation and hydration cycles. For this purpose, three samplings were carried out between August 2017 and August 2018, corresponding to potential periods 
of stress, during submersion and emersion periods, and several biochemical endpoints (photosynthetic pigments, $\mathrm{H}_{2} \mathrm{O}_{2}$, proline, LP, and thiols) were evaluated.

\section{Results}

\subsection{Photosynthetic Pigments}

Chlorophylls and carotenoids levels showed significant differences for the Species $\times$ Date interaction (Sp $\times \mathrm{Da}$; Table S1), indicating that the content of photosynthetic pigments of the three species studied was variable among the dates. Moreover, significant differences were detected between the two levels of the tide factor (low and high tide), regardless of species and date.

Fucus serratus exhibited the highest chlorophyll amount (Figure 1a) at low and high tides in August 2017, being 60\% and 100\% higher than those observed for P. canaliculata and A. nodosum, respectively. In the last sampling date (August 2018), the levels of chlorophyll of $F$. serratus and P. canaliculata were $130 \%$ and $60 \%$ higher at low tide than those of A. nodosum, respectively. Regarding differences between tides, the content of these pigments of $P$. canaliculata was significantly higher during low tide (up to $60 \%$ ) in all sampling dates, when compared to the high tide. On the other hand, F. serratus showed a more variable pattern in the amount of chlorophyll at low tide, with rises observed at low tide in August 2017 (50\%) and August 2018 (100\%). Ascophyllum nodosum showed no differences between tides.

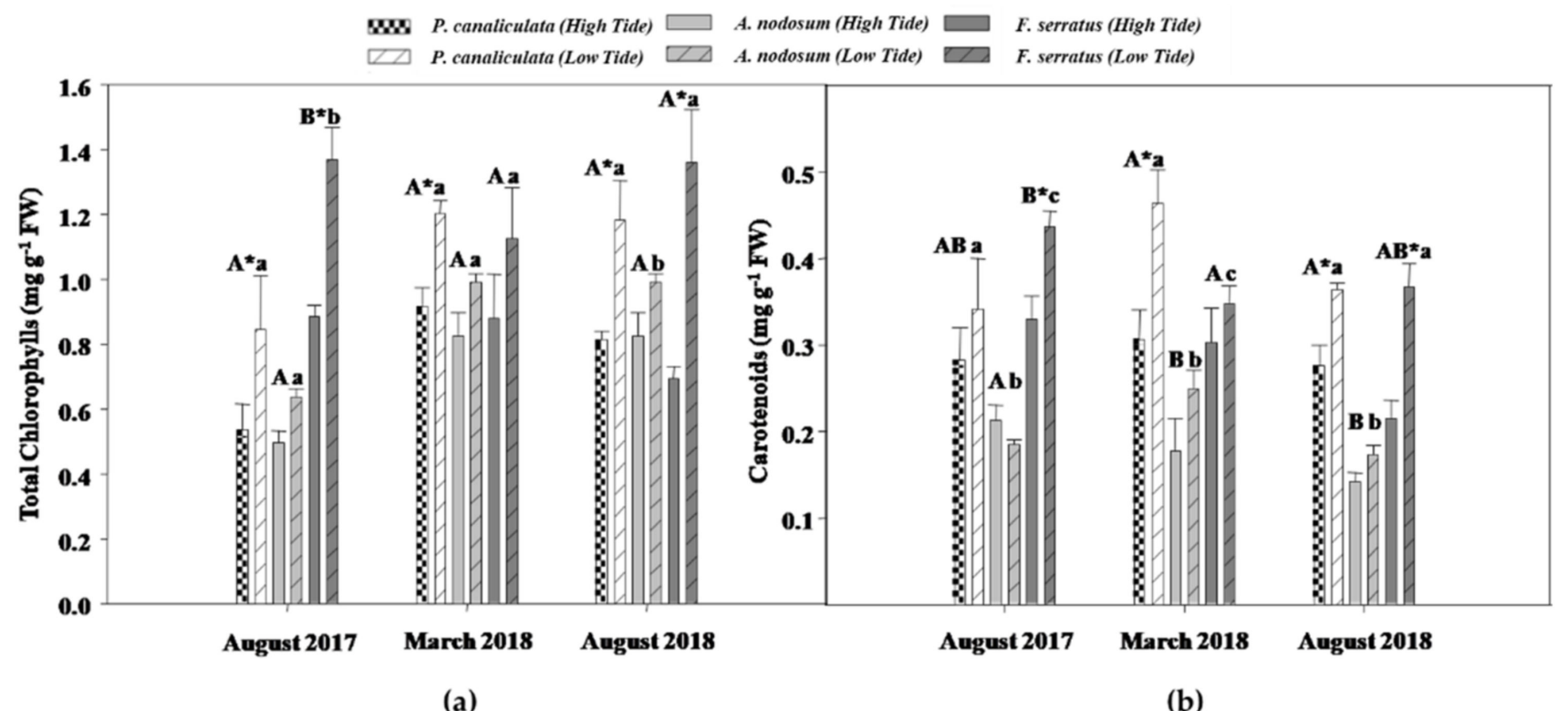

(a)

(b)

Figure 1. Photosynthetic pigments content of P. canaliculata, A. nodosum, and F. serratus at low and high tide conditions in August 2017, March and August 2018. (a) Total chlorophyll. (b) Carotenoids. Data presented are mean \pm STDEV $(n \geq 3) .{ }^{*}$ Above bars indicate significant statistical differences between tides at $p \leq 0.05$. Different uppercase letters indicate significant statistical differences between species at high tide at $p \leq 0.05$. Different lowercase letters indicate significant statistical differences between species at low tide at $p \leq 0.05$.

Regarding the carotenoids content (Figure 1b), in August 2017 and March 2018, the three species showed differences between them in low tide conditions, with A. nodosum having significantly lower levels than the remaining species in both sampling dates. Moreover, in August 2017, F. serratus had the highest levels of carotenoids, while P. canaliculata was the dominant species in March 2018. In terms of differences between low and high tides in the same species, an increase in the content of carotenoids at low tide was found in P. canaliculata in March (50\%) and August 2018 (30\%). The same pattern was also observed for F. serratus in August 2017 and August 2018, with rises at low tide conditions up to 70\%. No differences between tides were found for $A$. nodosum. 


\subsection{Redox Status}

Regarding $\mathrm{H}_{2} \mathrm{O}_{2}$ content, significant differences were recorded for the Species $\times$ Date interaction $(\mathrm{Sp} \times \mathrm{Da}$; Table $\mathrm{S} 2)$, indicating that the three species had variable levels of this ROS among the sampling dates.

In addition, since no significant differences between tides were detected, the results were presented as the average of both tides for each species and date. As shown in Figure 2a, $\mathrm{H}_{2} \mathrm{O}_{2}$ levels showed statistical differences between species in the three sampling dates: while P. canaliculata had the highest $\mathrm{H}_{2} \mathrm{O}_{2}$ content on both Summer dates (August 2017 and 2018), the same pattern was not observed in the Spring, where A. nodosum exhibited the highest amount of this ROS. Moreover, in August 2018, there were no differences in the $\mathrm{H}_{2} \mathrm{O}_{2}$ levels of $F$. serratus and $A$. nodosum.

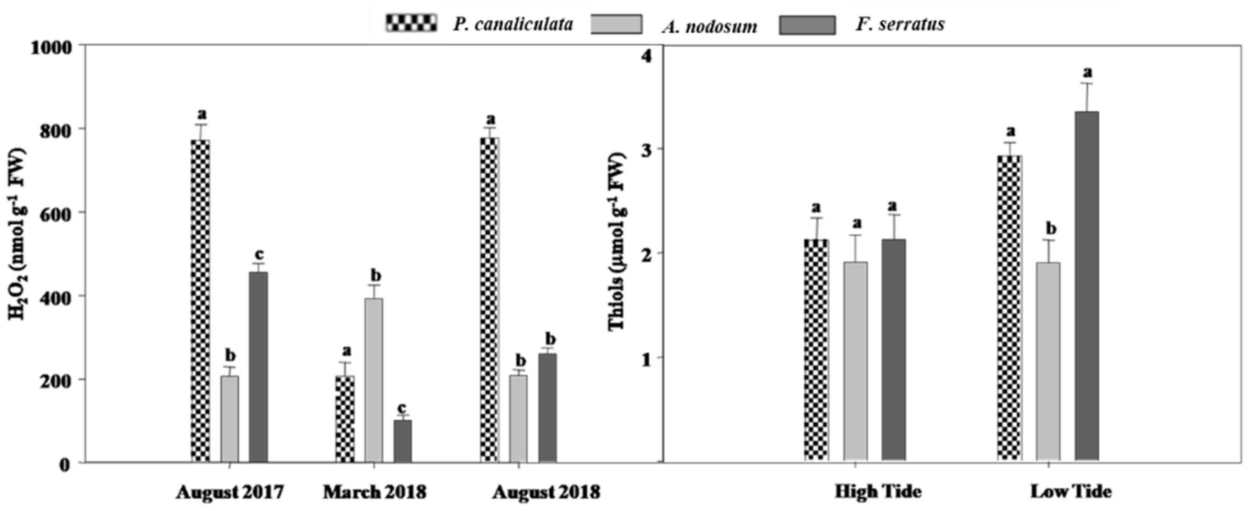

(a)

(b)

WW P. canaliculata (High Tide) $\square$ A. nodosum (High Tide) $\square$ F. serratus (High Tide)

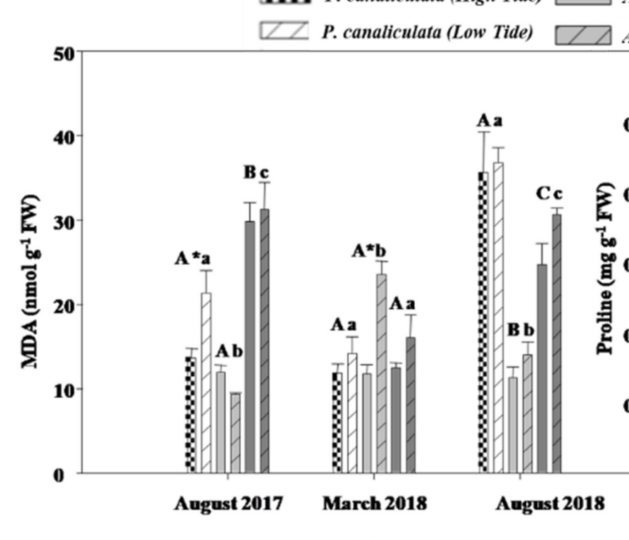

(c)

(d)

Figure 2. Oxidative stress indicators of P. canaliculata, A. nodosum, and F. serratus at low and high tide conditions in August 2017, March and August 2018. (a) $\mathrm{H}_{2} \mathrm{O}_{2}$. (b) Thiols. (c) MDA. (d) Proline. Data presented are mean $\pm \operatorname{STDEV}(n \geq 3)$. ${ }^{*}$ Above bars indicate significant statistical differences between tides at $p \leq 0.05$. Different uppercase letters indicate significant statistical differences between species at high tide at $p \leq 0.05$. Different lowercase letters indicate significant statistical differences between species at low tide at $p \leq 0.05$.

Concerning total thiols, significant differences for the Species $\times$ Tide interaction $(\mathrm{Sp} \times \mathrm{Ti}$; Table S3) were found.

Since no differences between sampling dates were detected, the results were presented as the average of each date, for the respective tidal regime, for each species. As can be seen, under a high tide, no differences between species were recorded (Figure 2c). However, at low tide, P. canaliculata and F. serratus presented the highest thiols levels, being $52 \%$ and $73 \%$ higher than those of $A$. nodosum, respectively.

The degree of LP was evaluated by quantifying malondialdehyde (MDA). The ANOVA analyses revealed significant differences regarding MDA levels for the Species $\times$ Tide $\times$ Date 
interaction $(\mathrm{Sp} \times \mathrm{Ti} \times \mathrm{Da}$; Table $\mathrm{S} 2)$. As can be seen in Figure $2 \mathrm{~b}, \mathrm{P}$. canaliculata and F. serratus had the highest MDA content in August 2017 and 2018, respectively, in the two tidal regimes. In March 2018 (date 2), MDA levels in A. nodosum were significantly increased when compared to those quantified for P. canaliculata and F. serratus at low tide.

Regarding tidal differences, on the first sampling date, P. canaliculata at low tide had significantly higher (60\%) MDA levels than at high tide, remaining similar between tides in March and August 2018. Ascophyllum nodosum showed an increase (100\%) of MDA under a low tide when compared to the high tide in March 2018. No difference between tides was found for F. serratus on all sampling dates.

Regarding proline content, ANOVA analyses revealed significant differences for the Species $\times$ Tide $\times$ Date interaction $(\mathrm{Sp} \times \mathrm{Ti} \times \mathrm{Da}$; Table S4).

Post-hoc analyses showed that in the first two sampling dates (August 2017 and March 2018), P. canaliculata had the lowest levels of proline (Figure 2d), followed by A. nodosum and F. serratus, while the opposite was found in date 3, where P. canaliculata had the highest levels of proline. Regarding tide effects within the same species, only A. nodosum and F. serratus displayed statistical differences between high and low tides: on dates 1 and 3 , the proline content of $A$. nodosum decreased and increased, respectively, $60 \%$ at low tide; on date 2 , the levels of this amino acid at low tide increased $30 \%$ in F. serratus.

\section{Discussion}

As a result of climate change, intertidal macroalgae will face an even more challenging habitat with extreme environmental conditions [13]. Influenced by this climatic instability, cold-water macroalgae are shifting their distribution patterns along the coastline, thus reducing their abundance in the southern limit areas of the Iberian Peninsula [9]. Therefore, it is of particular relevance to understanding the physiological responses of seaweeds to unfavorable conditions, in order to predict their adaptability in a future marked by climate change. Regarding this matter, although several laboratory studies have been conducted to assess the impact of single abiotic stressors (e.g., temperature, salinity, desiccation) on these organisms $[3,13,14]$, the physiological responses of macroalgae under field conditions can be quite distinct, thus highlighting the importance of these types of studies [12,15]. Thus, this work aimed to evaluate how three species (P. canaliculata, A. nodosum, and F. serratus) belonging to distinct intertidal levels, modulated their physiological processes between high and low tide periods, particularly exploring their redox status.

Changes in solar irradiance throughout the day and different tidal levels can influence the total amount of light that reaches intertidal species, making this a limiting and variable factor for these organisms [13]. Therefore, to regulate the number of photons absorbed by their photosynthetic apparatus, macroalgae have developed some photoprotective strategies, including the adjustment of the chloroplast orientation and repair mechanisms, activation of the xanthophyll cycle by carotenoids, and, particularly in the case of brown seaweeds, the accumulation of UV-absorbing phenolic compounds [16]. In this way, photosynthetically active cells can optimize the use of light, when organisms face conditions in which the amount of this factor compromises photosynthesis [13]. Our results showed that the content of photosynthetic pigments of all species increased during low tide, in some cases significantly, over the sampling dates. During long emersion periods, macroalgae suffer water loss, which strongly affects their photosynthetic rate due to the oxidation of pigments and proteins [3]. Despite this, the data herein collected points to an opposite trend. Yet, it should be highlighted that, during short-term desiccation, as was the case in this study, an increase in the levels of photosynthetic pigments can be observed [17]. In addition, the increase in carotenoids content may be related to its AOX capacity (in particular $\beta$-carotene) in the direct elimination of ${ }^{1} \mathrm{O}_{2}$, by quenching excited chlorophyll or dissipating excess energy via the xanthophyll cycle $[13,15]$. Furthermore, it was noticed that in almost all sampling dates, P. canaliculata had the highest content of carotenoids, followed by $F$. serratus and $A$. nodosum, regardless of the tidal regime. The high concentration of carotenoids in P. canaliculata has been previously observed [14], being pointed out as a 
photoprotective defense against UV radiation. Additionally, this species is known to promptly activate non-photochemical quenching mechanisms, such as the xanthophyll cycle, in order to reduce excess energy, converting violaxanthin into antheraxanthin and zeaxanthin, an important response mechanism to high light intensity [13]. On the other hand, the absence of changes in A. nodosum carotenoid levels between tides in all sampling dates may indicate that these pigments did not play a photoprotective role in this species, explaining the occurrence of oxidative stress.

Due to the instability of their habitat, the metabolic functions of intertidal macroalgae are constantly altered, increasing ROS production, which, in turn, can lead to oxidative stress $[3,12]$.

In the present study, the production of $\mathrm{H}_{2} \mathrm{O}_{2}$, an important ROS, the degree of LP, an oxidative stress biomarker, and the thiol content, indicative of cellular redox homeostasis, were evaluated. As proline has an important AOX and osmotic role, this metabolite was also quantified. Regarding $\mathrm{H}_{2} \mathrm{O}_{2}$ levels, no differences were found between the tides for the three species on all sampling dates, indicating that this ROS is not the best parameter to assess responses related to the tidal level. Contrary to these results, previous laboratory studies reported that under desiccation-induced stress, macroalgae had a higher $\mathrm{H}_{2} \mathrm{O}_{2}$ content when compared to the period of submersion [3,17]. The discrepancy between these results and those obtained in the present study may be precisely related to the conditions tested, since, in our study, the macroalgae were collected in their native environment, where the organisms were subjected to a combination of abiotic and biotic factors, which may lead to different responses from those obtained in laboratory experiments [12,15]. Despite the absence of differences between tides, the results were species-specific. F. serratus and P. canaliculata clearly presented higher levels of this ROS in August 2017 and 2018, corresponding to the two potential stress periods, with the maximum $\mathrm{H}_{2} \mathrm{O}_{2}$ content of all tested species achieved by P. canaliculata, although with no apparent change between tides, suggesting a great production of basal levels of ROS in this species. On the other hand, the levels of $\mathrm{H}_{2} \mathrm{O}_{2}$ in A. nodosum were the highest in March 2018. Due to the Mehler reaction, in which the $\mathrm{O}_{2}$ is reduced to $\mathrm{H}_{2} \mathrm{O}_{2}$, large amounts of this ROS are produced during photosynthesis [4]. Thus, the high $\mathrm{H}_{2} \mathrm{O}_{2}$ content of $A$. nodosum in the above-mentioned sampling dates pairs with the increase in chlorophyll content, suggesting a higher photosynthetic rate during that period of the year. Additionally, the $\mathrm{H}_{2} \mathrm{O}_{2}$ concentration quantified in this species were corroborated by those found for the MDA content, the latter showing the same pattern of variation, since there was a significant increase in the degree of LP at low tide in March 2018, that was accompanied by a small decrease in Pro levels. However, the redox homeostasis of the cell, which was evaluated by the total thiols, did not appear to be affected during low tide. Gathering all the results of A. nodosum, it might be suggested that this species suffered oxidative damage in March 2018 that was aggravated during low tide. Yet, $\mathrm{H}_{2} \mathrm{O}_{2}$ might not have been the ROS responsible for the rise of LP degree, which may support the role of $\mathrm{H}_{2} \mathrm{O}_{2}$ as a signaling molecule during photosynthesis [18]. The same response also seemed to occur in P. canaliculata in August 2017, as the LP degree significantly increased at low tide, despite the absence of differences in $\mathrm{H}_{2} \mathrm{O}_{2}$. It is known that $P$. canaliculata, by living on the upper shore of the intertidal, often faces several unfavorable conditions [13]. Thus, the oxidative damage of $P$. canaliculata was expected to be higher, when compared to the other two studied species. In accordance, our results showed that P. canaliculata presented the highest levels of $\mathrm{H}_{2} \mathrm{O}_{2}$, thiols, and MDA, regardless of the tidal regime, thus evidencing not only the harsh environment in which this species lives but also suggesting its high resilience [13]. Despite the physiological mechanisms of this species to withstand the extreme conditions still being unknown, some authors suggest the AOX role of carotenoids, corroborating the observed significantly higher levels of these pigments under low tide, and phlorotannins [14]. Regarding F. serratus, the species that live on the lowest shore of the intertidal, its oxidative damage, evidenced by $\mathrm{H}_{2} \mathrm{O}_{2}, \mathrm{MDA}$, and thiols content, was often higher than A. nodosum during the low tide of August 2017 and 2018, demonstrating the high sensitivity of $F$. serratus. In fact, it was suggested that algae species 
living at the low intertidal cannot overcome the excess of ROS during low tide, while the ones that live in the top limits of the intertidal possess mechanisms that successfully minimize the oxidative damage imposed by their habitat [3]. Furthermore, F. serratus presented similar or higher levels of some parameters (e.g., thiols and MDA content) than those of P. canaliculata, demonstrating the vulnerability of $F$. serratus to variability between tides. A previous study, which evaluated the influence of the vertical distribution of macroalgae in the intertidal on stress resilience of three species (F. distichus, F. spiralis, F. evanescens), found similar levels of MDA between F. distichus, found at the lowest intertidal level, and F. spiralis, which occupied a higher position on the shore when exposed to freezing and desiccation-induced stress [10]. Paired with these results, the present study supported the evidence that macroalgae species that face low periods of emergence are more susceptible to unfavorable conditions, reaching similar levels of oxidative damage to species that are almost permanently exposed to several abiotic stressors.

Although thiols content of F. serratus and P. canaliculata were significantly higher than A. nodosum, there were no differences between tides, although the observed tendency for increased levels of these compounds during low tide, mainly in P. canaliculata. These results may suggest the role of some thiol-containing compounds, such as GSH, in the response of these algae species to their unstable habitat. Proline levels of P. canaliculata showed no differences between tides in the three sampling dates, suggesting that proline appears not to have been involved in the AOX response of this species. The proline content in F. serratus increased at low tide, particularly in March 2018, supporting the osmoprotective role of this amino acid and its action as a membrane stabilizer, preventing the increase of LP [4].

\section{Materials and Methods}

\subsection{Sampling Procedure and Experimental Design}

Individuals of $P$. canaliculata, A. nodosum, and F. serratus were collected in Viana do Castelo, Portugal (between $41^{\circ} 43^{\prime} 0.3^{\prime \prime} \mathrm{N}$ and $41^{\circ} 41^{\prime} 36.36^{\prime \prime} \mathrm{N} ; 8^{\circ} 51^{\prime} 10.52^{\prime \prime} \mathrm{W}$ ), since it is the only shore where these three species coexist at their southern limit of distribution. Sampling was conducted on three distinct dates: August 2017, March 2018, and August 2018, under low and high tidal regimes.

All the organisms were collected at the middle of the high tide period, corresponding to a time where species were in their optimal growth conditions, and at the end of the low tide, right before the water reached the respective intertidal level of each species. During the high tide period, water depth was $0.5-0.75 \mathrm{~m}$ for P. canaliculata, $1.0-1.30 \mathrm{~m}$ for A.nodosum, and F. serratus, the species belonging to the lowest intertidal level, covered by 2.0-3.0 m seawater. Furthermore, at low tide, sampling was conducted immediately before the water covered the species to achieve the maximum exposure period for each studied macroalgae species. Considering that throughout a tidal cycle, which has a $12 \mathrm{~h}$ period and corresponds to low and high tide periods, the longest emersion time was recorded for P. canaliculata at $10 \mathrm{~h}$, while A. nodosum and F. serratus were exposed during $8 \mathrm{~h}$ and $4 \mathrm{~h}$, respectively. Since the main goal was to verify how macroalgae living in distinct intertidal levels responded to different tidal regimes, the chosen dates corresponded to potential periods of stress (two during summer and one during spring), as these macroalgae are known as cold-water species. Information about water temperature, atmospheric temperature, and UVB irradiance, which was calculated through UV index (http:/ / www.ipma.pt/pt/oclima/monitoriza.dia/; accessed on 20 July 2021) and according to the formula $\left[\mathrm{UVB}_{280-315} \mathrm{~nm}\left(\mu \mathrm{W} \mathrm{cm}{ }^{-2}\right)=7.55 \times\right.$ UVEry (correspondent to erythemal weighted UV radiation)] described by McKenzie et al. [19], for each sampling date is summarized in Table 1. 
Table 1. Information about water temperature and atmospheric temperature, UV index, and UVB irradiance during low and high tides of all sampling dates.

\begin{tabular}{|c|c|c|c|c|c|c|c|c|}
\hline \multirow[b]{2}{*}{$\begin{array}{l}\text { Sampling } \\
\text { Date }\end{array}$} & \multicolumn{4}{|c|}{ Low Tide } & \multicolumn{4}{|c|}{ High Tide } \\
\hline & $\begin{array}{c}\text { Water } \\
\text { Temperature } \\
\left({ }^{\circ} \mathrm{C}\right)\end{array}$ & $\begin{array}{c}\text { Atmospheric } \\
\text { Temperature } \\
\left({ }^{\circ} \mathrm{C}\right)\end{array}$ & $\begin{array}{c}\text { UV } \\
\text { Index }\end{array}$ & $\begin{array}{c}\text { UVB } \\
\text { Irradiance } \\
\left(\mu W \mathrm{~cm}^{-2}\right)\end{array}$ & $\begin{array}{c}\text { Water } \\
\text { Temperature } \\
\left({ }^{\circ} \mathrm{C}\right)\end{array}$ & $\begin{array}{c}\text { Atmospheric } \\
\text { Temperature } \\
\left({ }^{\circ} \mathrm{C}\right)\end{array}$ & $\begin{array}{c}\text { UV } \\
\text { Index }\end{array}$ & $\begin{array}{c}\text { UVB } \\
\text { Irradiance } \\
\left(\mu \mathrm{W} \mathrm{cm}^{-2}\right)\end{array}$ \\
\hline 17-Aug & 17.1 & 22 & 7 & 132.1 & 16.8 & 24 & 9 & 169.9 \\
\hline 18-Mar & 12.7 & 9 & 4 & 75.5 & 12.5 & 9 & 4 & 75.5 \\
\hline 18-Aug & 14.1 & 24 & 8 & 151 & 15.3 & 21 & 8 & 151 \\
\hline
\end{tabular}

Since this work was conducted under field conditions, to minimize the effects of intrinsic variability, for each date and tidal period, five biological replicates of each macroalgae species were collected. Immediately after cutting, macroalgae were frozen in liquid nitrogen. Upon arrival to the laboratory, the plant material was ground into liquid nitrogen and stored at $-80^{\circ} \mathrm{C}$ for subsequent biochemical procedures.

\subsection{Biochemical Endpoints}

\subsubsection{Extraction and Quantification of Photosynthetic Pigments}

The content of total chlorophylls and carotenoids was quantified according to Lichtenthaler [20]. Frozen samples were homogenized in $80 \%(v / v)$ acetone and centrifuged at $1400 \times g$ for $10 \mathrm{~min}$. Afterward, the absorbance at 470, 647, and $663 \mathrm{~nm}$ was recorded and the chlorophylls and carotenoids levels were calculated using the formulas of Lichtenthaler [20]. Results were expressed as $\mathrm{mg} \mathrm{g}^{-1}$ fresh weight (f.w.).

\subsubsection{Hydrogen Peroxide $\left(\mathrm{H}_{2} \mathrm{O}_{2}\right)$ Determination}

$\mathrm{H}_{2} \mathrm{O}_{2}$ quantification was performed following the procedures of Jana and Choudhury [21]. Samples were homogenized on ice in $50 \mathrm{mM}$ potassium phosphate buffer ( $\mathrm{pH}$ 6.5) and centrifuged at $6000 \times g$ for $25 \mathrm{~min}$. Then, the supernatant was mixed with $0.1 \%(v / v)$ $\mathrm{TiSO}_{4}$ in $20 \%(v / v) \mathrm{H}_{2} \mathrm{SO}_{4}$, and samples were vigorously vortexed and centrifuged in the same conditions as previously described. Finally, the absorbance at $410 \mathrm{~nm}$ was measured and the $\mathrm{H}_{2} \mathrm{O}_{2}$ content was calculated using the extinction coefficient of $0.28 \mu \mathrm{M}^{-1} \mathrm{~cm}^{-1}$. The results were expressed in $\mathrm{nmol} \mathrm{g}^{-1}$ f.w.

\subsubsection{Evaluation of Lipid Peroxidation (LP)}

LP was evaluated through the measurement of malondialdehyde (MDA) content by the method of Heath and Packer [22]. After homogenization of the samples in $0.1 \%(w / v)$ trichloroacetic acid (TCA) and centrifugation $(10,000 \times g ; 5 \mathrm{~min})$, the supernatant reacted with $0.5 \%$ thiobarbituric acid in $20 \%(w / v)$ TCA for $30 \mathrm{~min}$ at $95^{\circ} \mathrm{C}$. Tubes were then cooled and centrifuged $(10,000 \times \mathrm{g} ; 7 \mathrm{~min})$, and the absorbances at 532 and $600 \mathrm{~nm}$ were recorded. To minimize the unspecific turbidity, the obtained values at $600 \mathrm{~nm}$ were subtracted to the ones of $532 \mathrm{~nm}$. Finally, the levels of MDA were estimated through the extinction coefficient of $155 \mathrm{mM}^{-1} \mathrm{~cm}^{-1}$ and expressed as $\mathrm{nmol}^{-1}$ f.w.

\subsubsection{Quantification of Total Thiols}

The spectrophotometrical quantification of thiols was achieved following the procedure described by Zhang et al. [23]. Samples were homogenized, on ice, in a solution of $20 \mathrm{mM}$ EDTA and $20 \mathrm{mM}$ ascorbic acid and centrifuged at $13,000 \times \mathrm{g}$ for $20 \mathrm{~min}$ at $4{ }^{\circ} \mathrm{C}$. Then, $200 \mathrm{mM}$ Tris- $\mathrm{HCl}$ (pH 8.2) and $10 \mathrm{mM}$ 5,5'-dithiobis (2-nitrobenzoic acid) was added to the supernatant. Mixtures were incubated for $15 \mathrm{~min}$ at room temperature and the absorbance was then registered at $412 \mathrm{~nm}$. The extinction coefficient of $13,600 \mathrm{M}^{-1} \mathrm{~cm}^{-1}$ was used to calculate the levels of total thiols, being the results expressed as nmol $\mathrm{g}^{-1}$ f.w. 


\subsubsection{Proline Quantification}

Proline quantification was conducted according to Bates et al. [24], using the ninhydrin colorimetric assay. Macroalgae samples were homogenized in 3\% $(w / v)$ sulphosalicylic acid and centrifuged at $500 \times g$ for $10 \mathrm{~min}$, followed by an incubation period of $1 \mathrm{~h}$ at $95^{\circ} \mathrm{C}$, in which the supernatant was mixed with glacial acetic acid and ninhydrin. Finally, toluene was added to extract the proline-ninhydrin complex and the absorbance was recorded at $520 \mathrm{~nm}$. The levels of proline were calculated using a calibration curve, previously prepared with known concentrations of this amino acid, and results were expressed in $\mathrm{mg} \mathrm{g}^{-1}$ f.w.

\subsection{Statistical Analysis}

For each species, five individuals were collected on each date and for each tide regime. All the laboratory procedures were conducted, at least, in triplicate for each replicate to control the quality of the procedure. Results are expressed as mean \pm standard deviation (STDEV) of the five replicates. To explore the differences between the considered factors, a three-way ANOVA was conducted, being the species (A. nodosum, F. serratus, and $P$. canaliculata) and the tide (low and high) defined as fixed factors, and the date as a random factor. Whenever significant $(p<0.05)$, the ANOVAs were followed by the posthoc test of Student-Newman-Keuls (SNK).

\section{Conclusions}

In a climate change-related scenario, understanding intertidal macroalgae responses towards environmental disturbances in field conditions is of utmost importance, in order to predict future distributional patterns of these species along the coastline. Thus, the results of this work strengthen that macroalgae that live at different levels of the intertidal show species-signature physiological responses, being able to modulate their stress responses to the environmental conditions found between high and low tides. Indeed, in the present study, P. canaliculata showed a more stable redox status between the two tidal periods in all sampling dates, while F. serratus, the species living at the lowest level of the intertidal, presented higher oxidative damage in the low tide period. Overall, the physiological responses analyzed were species-specific, demonstrating that low intertidal organisms such as F. serratus, which currently live in a more protected environment, were more susceptible to low tide, suggesting that at least this species will probably be dramatically affected by the expected effects of climate change.

Supplementary Materials: The following are available online at https:/ /www.mdpi.com/article/10 .3390/plants10091892/s1, Table S1: Summary of ANOVAs for chlorophyll and carotenoid contents of P. canaliculata, A. nodosum and F. serratus at low and high tide conditions in August 2017, March and August 2018, Table S2: Summary of ANOVAs for $\mathrm{H} 2 \mathrm{O} 2$ and MDA levels of P. canaliculata, A. nodosum and F. serratus at low and high tide conditions in August 2017, March and August 2018, Table S3: Summary of ANOVAs for thiols levels of P. canaliculata, A. nodosum and F. serratus at low and high tide conditions in August 2017, March and August 2018, Table S4: Summary of ANOVAs for proline levels of P. canaliculata, A. nodosum, F. serratus and at low and high tide conditions in August 2017, March and August 2018.

Author Contributions: Conceptualization, M.R., C.S., A.C.T., F.F., P.V.; Methodology, M.M., B.S., C.S., I.F., A.C.T., Formal analysis, M.R.; Resources, M.R., I.S.-P., and F.F.; Writing-original draft preparation, M.M.; Writing — review and editing, M.M., C.S., B.S., M.R. and F.F. Supervision: M.R., F.F. All authors have read and agreed to the published version of the manuscript.

Funding: This research was funded by the Project Val-Wrack (POCI-01-0145-FEDER-029818), cofinanced by COMPETE 2020, Portugal 2020, the EU through the ERDF and by national funds through FCT-Foundation for Science and Technology within the scope of UID/Multi/04423/2019 (CIIMAR), UIDB/05748/2020 and UIDP/05748/2020 (GreenUPorto). M. Martins, C. Soares, B. Sousa and A.C. Torres acknowledge the support by grants (MM: SFHR/BD/143268/2019; CS: SFRH/BD/115643/2016; BS: 2020.07826.BD; ACT: SFRH/BD/114935/2016) from FCT. 
Institutional Review Board Statement: Not applicable.

Informed Consent Statement: Not applicable.

Data Availability Statement: The data presented in this study are available in this manuscript.

Conflicts of Interest: The authors declare no conflict of interest. The funders had no role in the design of the study; in the collection, analyses, or interpretation of data; in the writing of the manuscript, or in the decision to publish the results.

\section{References}

1. Kumar, M.; Kumari, P.; Reddy, C.R.K.; Jha, B. Chapter Four-Salinity and Desiccation Induced Oxidative Stress Acclimation in Seaweeds. In Advances in Botanical Research; Bourgougnon, N., Ed.; Academic Press: Cambridge, MA, USA, 2014; Volume 71, pp. 91-123.

2. Davison, I.R.; Pearson, G.A. Stress Tolerance in Intertidal Seaweeds. J. Phycol. 1996, 32, 197-211. [CrossRef]

3. Flores-Molina, M.R.; Thomas, D.; Lovazzano, C.; Núñez, A.; Zapata, J.; Kumar, M.; Correa, J.A.; Contreras-Porcia, L. Desiccation stress in intertidal seaweeds: Effects on morphology, antioxidant responses and photosynthetic performance. Aquat. Bot. 2014, 113, 90-99. [CrossRef]

4. Soares, C.; Carvalho, M.E.A.; Azevedo, R.A.; Fidalgo, F. Plants facing oxidative challenges-A little help from the antioxidant networks. Environ. Exp. Bot. 2019, 161, 4-25. [CrossRef]

5. Araújo, R.M.; Serrao, E.A.; Sousa-Pinto, I.; Åberg, P. Spatial and temporal dynamics of fucoid populations (Ascophyllum nodosum and Fucus serratus): A comparison between central and range edge populations. PLoS ONE 2014, 9, e92177. [CrossRef]

6. Seeley, R.H.; Schlesinger, W.H. Sustainable seaweed cutting? The rockweed (Ascophyllum nodosum) industry of Maine and the Maritime Provinces. Ann. N. Y. Acad. Sci. 2012, 1249, 84-103. [CrossRef]

7. Pfetzing, J.; Stengel, D.B.; Cuffe, M.M.; Savage, A.V.; Guiry, M.D. Effects of Temperature and Prolonged Emersion on Photosynthesis, Carbohydrate Content and Growth of the Brown Intertidal Alga Pelvetia canaliculata. Bot. Mar. 2000, 43, $399-407$. [CrossRef]

8. Belkin, I.M. Rapid warming of Large Marine Ecosystems. Prog. Oceanogr. 2009, 81, 207-213. [CrossRef]

9. Casado-Amezúa, P.; Araújo, R.; Bárbara, I.; Bermejo, R.; Borja, Á.; Díez, I.; Fernández, C.; Gorostiaga, J.M.; Guinda, X.; Hernández, I.; et al. Distributional shifts of canopy-forming seaweeds from the Atlantic coast of Southern Europe. Biodivers. Conserv. 2019, 28, 1151-1172. [CrossRef]

10. Collén, J.; Davison, I.R. Reactive oxygen production and damage in intertidal fucus spp. (Phaeophyceae). J. Phycol. $1999,35,54-61$. [CrossRef]

11. Guenther, R.J.; Martone, P.T. Physiological performance of intertidal coralline algae during a simulated tidal cycle. J. Phycol. 2014, 50, 310-321. [CrossRef] [PubMed]

12. Maharana, D.; Das, P.B.; Verlecar, X.N.; Pise, N.M.; Gauns, M. Oxidative stress tolerance in intertidal red seaweed Hypnea musciformis (Wulfen) in relation to environmental components. Environ. Sci. Pollut. Res. 2015, 22, 18741-18749. [CrossRef]

13. Fernández-Marín, B.; Míguez, F.; Becerril, J.M.; García-Plazaola, J.I. Activation of violaxanthin cycle in darkness is a common response to different abiotic stresses: A case study in Pelvetia canaliculata. BMC Plant Biol. 2011, 11, 181. [CrossRef] [PubMed]

14. Hupel, M.; Lecointre, C.; Meudec, A.; Poupart, N.; Gall, E.A. Comparison of photoprotective responses to UV radiation in the brown seaweed Pelvetia canaliculata and the marine angiosperm Salicornia ramosissima. J. Exp. Mar. Biol. Ecol. 2011, 401, 36-47. [CrossRef]

15. Sampath-Wiley, P.; Neefus, C.D.; Jahnke, L.S. Seasonal effects of sun exposure and emersion on intertidal seaweed physiology: Fluctuations in antioxidant contents, photosynthetic pigments and photosynthetic efficiency in the red alga Porphyra umbilicalis Kützing (Rhodophyta, Bangiales). J. Exp. Mar. Biol. Ecol. 2008, 361, 83-91. [CrossRef]

16. Connan, S.; Deslandes, E.; Ar Gall, E. Influence of day-night and tidal cycles on phenol content and antioxidant capacity in three temperate intertidal brown seaweeds. J. Exp. Mar. Biol. Ecol. 2007, 349, 359-369. [CrossRef]

17. Kumar, M.; Gupta, V.; Trivedi, N.; Kumari, P.; Bijo, A.J.; Reddy, C.R.K.; Jha, B. Desiccation induced oxidative stress and its biochemical responses in intertidal red alga Gracilaria corticata (Gracilariales, Rhodophyta). Environ. Exp. Bot. 2011, 72, 194-201. [CrossRef]

18. Osmond, C.B.; Foyer, C.H.; Bock, G.; Noctor, G.; Veljovic-Jovanovic, S.; Foyer, C.H. Peroxide processing in photosynthesis: Antioxidant coupling and redox signalling. Philos. Trans. R. Soc. Lond. Ser. B 2000, 355, 1465-1475. [CrossRef]

19. McKenzie, R.; Smale, D.; Kotkamp, M. Relationship between UVB and erythemally weighted radiation. Photochem. Photobiol. Sci. 2004, 3, 252-256. [CrossRef] [PubMed]

20. Lichtenthaler, H.K. Chlorophylls and carotenoids: Pigments of photosynthetic biomembranes. In Methods in Enzymology 1987; Academic Press: Cambridge, MA, USA, 1987; Volume 148, pp. 350-382.

21. Jana, S.; Choudhuri, M.A. Glycolate metabolism of three submersed aquatic angiosperms during ageing. Aquat. Bot. 1982, 12, 345-354. [CrossRef]

22. Heath, R.L.; Packer, L. Photoperoxidation in isolated chloroplasts: I. Kinetics and stoichiometry of fatty acid peroxidation. Arch. Biochem. Biophys. 1968, 125, 189-198. [CrossRef] 
23. Zhang, H.; Lian, C.; Shen, Z. Proteomic identification of small, copper-responsive proteins in germinating embryos of Oryza sativa. Ann. Bot. 2009, 103, 923-930. [CrossRef] [PubMed]

24. Bates, L.S.; Waldren, R.P.; Teare, I.D. Rapid determination of free proline for water-stress studies. Plant Soil 1973, 39, $205-207$. [CrossRef] 